\title{
Fatigue crack growth in heat-treated aluminium alloys
}

\author{
L.P. Borrego ${ }^{\mathrm{a}, *}$, J.M. Costa ${ }^{\text {b }}$, F.V. Antunes ${ }^{\text {b }}$, J.M. Ferreira ${ }^{\mathrm{b}}$ \\ a Department of Mechanical Engineering, Instituto Superior de Engenharia de Coimbra, IPC, Rua Pedro Nunes, $3030-199$ Coimbra, Portugal \\ ${ }^{\mathrm{b}}$ Department of Mechanical Engineering, University of Coimbra, Polo II, Pinhal de Marrocos, 3030-201 Coimbra, Portugal
}

\section{A R T I C L E I N F O}

\section{Article history:}

Available online $\mathrm{xxxx}$

\section{Keywords:}

Aluminium alloys

Crack propagation

Crack closure

\begin{abstract}
A B S T R A C T
Fatigue crack propagation tests have been performed in several heat-treated aluminium alloys under constant amplitude loading. All experiments were performed, in load control, in a servo-hydraulic closed-loop mechanical test machine. The tests were carried out using middle tension, $\mathrm{M}(\mathrm{T})$, specimens. The influence of stress ratio and thickness were analysed. Crack closure was monitored in all tests by the compliance technique using a pin microgauge. A strong stress ratio and material dependence effects on the fatigue crack growth were observed. These effects are discussed in terms of the different dominant closure mechanism. The crack growth behaviour of heat-treated aluminium alloys depends mainly on whether the dominant closure mechanism is plasticity-induced or roughness-induced. The enhancement of roughness-induced closure promotes higher crack growth resistance in these alloys. Roughness-induced closure dominates crack closure in aluminium alloys age hardened by naturally ageing and also artificially aged alloys with higher contents of $\mathrm{Mn}$ and $\mathrm{Cr}$ elements. In alloys aged hardened by artificially ageing and simultaneously with a lower content of these alloying elements plasticity-induced closure is dominant.
\end{abstract}

(c) 2008 Elsevier Ltd. All rights reserved.

\section{Introduction}

Crack closure has played a central role in the study of fatigue crack propagation. A large number of researches have made attempts to understand the influence of the mean stress on the fatigue crack growth rate based on the crack closure argument (e.g. $[1,2])$.

Except for high stress ratios or high $\Delta K$ values, the fatigue crack growth can be affected more or less by the crack closure induced by plasticity in the two-parameter crack growth rate relation zone, Paris regime, or by oxidation and surface roughness in the near threshold regime. The influence of mean stress on the fatigue crack growth rate has been explained with success by the crack closure using the normalized load parameter $U$ [2].

It is generally accepted that fatigue crack growth in the Paris regime is only weakly dependent on the materials microstructure when represented against $\Delta K_{\mathrm{eff}}$ [3]. However, when $\mathrm{d} a / \mathrm{d} N$ is plotted against $\Delta K$ a number of examples of microstructure-dependent fatigue crack growth were reported in the literature (e.g. [3-5]).

In a work of Bergner and Zouhar [4] crack growth rates of various aluminium alloys were observed to vary by a factor of about 20 at some values of $\Delta K$. They suggests the presence of material-dependent effects of crack closure and environment to explain that discrepancies.

Fatigue crack growth in Al-Mg-Si alloys can be highly influenced by the dispersoid content due to $\mathrm{Mn}$ or $\mathrm{Cr}$ being present [6] as well as by the type of age-hardening heat treatment [4-6].

\footnotetext{
* Corresponding author. Tel.: +351 962560101; fax: +351 239790331.

E-mail address: borrego@isec.pt (L.P. Borrego).
} 
In all cases, accordingly with Bergner and Zouhar [4], the crack growth behaviour depends mainly on whether an alloy presents plasticity-induced crack closure only, or additionally other retarding mechanisms such as roughness-induced closure $[5,6]$.

The present work intends to analyse the fatigue crack propagation in heat-treated aluminium alloys. For this purpose, fatigue crack propagation tests have been performed in 2017-T4 aluminium alloy as well as in 6082-T6 aluminium alloys with different $\mathrm{Mn}$ and $\mathrm{Cr}$ contents. The influence of stress ratio and thickness is analysed.

\section{Experimental details}

This research was conduced using AlCuMgSi (2017) aluminium alloy with a T4 heat treatment as well as AlMgSi1 (6082) aluminium alloys with a T6 heat treatment. The T4 and the T6 treatments are full heat treatment processes comprising the operations of solution treatment, quenching and age-hardening. The age-hardening of the T4 heat treatment is performed at room temperature (naturally ageing) while in T6 is performed by artificially ageing $\left(160^{\circ} \mathrm{C}\right.$ during $10 \mathrm{~h}$ for 6082 aluminium alloy).

The alloys' chemical composition and mechanical properties are shown in Tables 1 and 2, respectively. Alloys 6082T6(A) and 6082-T6(B) differ mainly in the manganese and chromium contents.

Fatigue tests were undertaken, in agreement with ASTM E647 [7] standard, using middle-tension, M(T), specimens. For 2017-T4 aluminium alloy 1.8 and $10 \mathrm{~mm}$ thickness specimens were used. The thickness of 6082-T6 aluminium alloy specimens was $3 \mathrm{~mm}$ (alloy A) and $6 \mathrm{~mm}$ (alloy B). The specimens were obtained in the longitudinal transverse direction from a laminated plate. Fig. 1 illustrates the major dimensions of the samples used in the tests. The notch preparation was made by electrical-discharge machining. After that, the specimen surfaces were mechanically polished.

All experiments were performed in a servohydraulic, closed-loop mechanical test machine with $100 \mathrm{kN}$ capacity, interfaced to a computer for machine control and data acquisition. All tests were conducted in air and room temperature, at a frequency of $20 \mathrm{~Hz}$ and a stress ratio of 0 or 0.4 . The specimens were clamped by hydraulic grips. The crack length was measured using a travelling microscope $(45 \times)$ with an accuracy of $10 \mu \mathrm{m}$. Collection of data was initiated after achieving an initial crack length $2 a_{0}$ of approximately $12 \mathrm{~mm}$. The tests where performed in load control mode. Crack growth rates were determined by the incremental polynomial method using five consecutive points [7].

Load-displacement behaviour was monitored at specific intervals throughout each of the tests using a pin microgauge elaborated from a high sensitive commercial axial extensometer $( \pm 0.625 \mathrm{~mm}$ of maximum displacement). The gauge pins were placed in two drilled holes of $0.5 \mathrm{~mm}$ diameter located above and below the centre of the notch (see Fig. 1). The distance between these holes was $3.5 \mathrm{~mm}$. In order to collect as many load-displacement data as possible during a particular cycle, the frequency was reduced to $0.5 \mathrm{~Hz}$. Noise on the strain gauge output was reduced by passing the signal through a $1 \mathrm{~Hz}$ low-pass mathematical filter.

Variations of the opening load, Pop, were derived from these records using the technique known as maximization of the correlation coefficient [8]. This technique involves taking the upper $10 \%$ of the $P-\delta$ data and calculating the least squares correlation coefficient. The next data pair is then added and the correlation coefficient is again computed. This procedure is repeated for the whole data set. The point at which the correlation coefficient reaches a maximum can then be defined as Pop.

The fraction of the load cycle for which the crack remains fully open, parameter $U$, was calculated by the following equation:

$$
U=\frac{K_{\max }-K_{\mathrm{op}}}{K_{\max }-K_{\min }}
$$

where $K_{\max }, K_{\min }$, and $K_{\mathrm{op}}$ are the maximum, minimum and crack opening stress intensity factor, respectively. The values of the effective $K$ range parameter, $\Delta K_{\text {eff, }}$ were than calculated by the expression

$$
\Delta K_{\text {eff }}=K_{\max }-K_{\text {op }}=U \Delta K
$$

The fatigued fracture surfaces roughness was evaluated. The laser equipment Mahr RM600-3D was used for these measurements. The optical distance sensor works with an infrared laser whose beam is focused on the surface of the sample. The size of the spot is $1 \mu \mathrm{m}$ and the resolution of the equipment is $0.01 \mu \mathrm{m}$. The geometry of the surface of fatigue specimens was determined through analysis of profiles of the fracture surface, parallel to the main crack propagation direction.

Table 1

Chemical composition of the analysed alloys (weight\%).

\begin{tabular}{llllll}
\hline Alloy & Si & Mg & Mn & Fe & Cr \\
\hline 2017-4 & 0.50 & 0.60 & 0.70 & 0.40 & 0.10 \\
6082-T6 (alloy A) & 1.05 & 0.80 & 0.68 & 0.26 & 0.01 \\
6082-T6 (alloy B) & 0.98 & 1.08 & 0.90 & 0.32 & 0.04 \\
\hline
\end{tabular}


Table 2

Mechanical properties of the aluminium alloys.

\begin{tabular}{lllr}
\hline Alloy & $\sigma_{\mathrm{UTS}}(\mathrm{MPa})$ & $\sigma_{\mathrm{YS}}(\mathrm{MPa})$ & \\
\hline 2017-T4 & 427 & 272 & $\varepsilon_{\mathrm{r}}(\%)$ \\
6082-T6 (alloy A) & $300 \pm 2.5$ & $245 \pm 2.7$ & 9 \\
6082-T6 (alloy B) & $290 \pm 1.9$ & $250 \pm 2.4$ & 12 \\
\hline
\end{tabular}

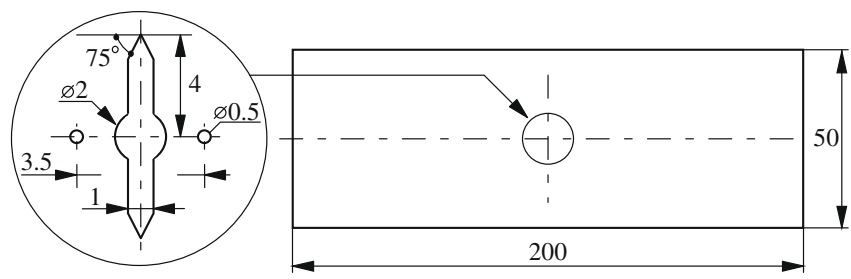

Fig. 1. Geometry of the $\mathrm{M}(\mathrm{T})$ specimen used (dimensions in $\mathrm{mm}$ ).

\section{Results and discussion}

The influence of stress ratio and thickness on the fatigue crack growth rate for aluminium alloy 2017-T4 can be seen in Fig. 2. The data was obtained using specimen thickness of 1.8 and $10 \mathrm{~mm}$ tested at stress ratios of $R=0$ and $R=0.4$. The fatigued fracture surface of the $10 \mathrm{~mm}$ thickness specimen tested under $R=0$ is superimposed in the figure for comparison.

A strong $R$-ratio effect on the fatigue crack growth rate was observed for $1.8 \mathrm{~mm}$ thickness specimens. The same behaviour was also observed for $10 \mathrm{~mm}$ thickness specimens, but only for $\Delta K$ values lower than $9 \mathrm{MPa} \mathrm{m}^{1 / 2}$. The crack growth rate $\mathrm{d} a / \mathrm{d} N$ generally increases with the stress ratio $R$. For aluminium alloy 6082-T6 only a moderate $R$-ratio is generally observed as reported in previous work [9].

Fig. 2 shows that specimen thickness has no significant influence in the crack growth behaviour of this alloy except for $R=0$ and for $\Delta K$ values above $9 \mathrm{MPa} \mathrm{m}^{1 / 2}$.

Indeed the crack growth behaviour observed for the $10 \mathrm{~mm}$ thickness specimen tested at $R=0$ is quite uncommon. This behaviour was so unexpected that two more testes were performed under the same condition, which showed similar trends and thus confirmed the crack growth rates depicted in Fig. 2. The crack growth rate curve for the $10 \mathrm{~mm}$ thickness under $R=0$ presents three distinct regions. Initially, for $\Delta K$ values lower than $9 \mathrm{MPa} \mathrm{m}^{1 / 2}, \mathrm{~d} a / \mathrm{d} N$ values are similar to the crack growth rates observed for $1.8 \mathrm{~mm}$ thickness specimen tested at the same $R$. Then a transition period is observed for $\Delta K$ val-

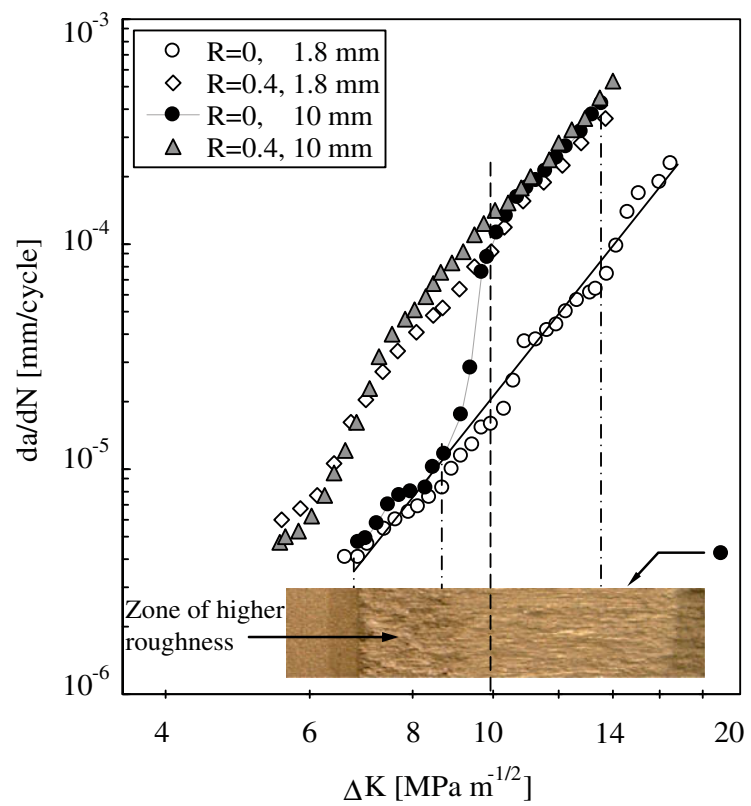

Fig. 2. Effect of stress ratio and specimen thickness on fatigue crack growth rate for alloy 2017-T4. 
ues between 9 and $10 \mathrm{MPa} \mathrm{m}^{1 / 2}$. Finally, for $\Delta K$ values above $10 \mathrm{MPa} \mathrm{m}^{1 / 2}$, the crack growth rates present approximately the same values as the ones obtained for $R=0.4$.

This behaviour is attributed to the abrupt change of the propagation mechanisms in this test condition, which promotes initially a fatigued fracture surface of higher roughness and then a lower roughness surface zone as observed in Fig. 3 (see also Fig. 2). Therefore, for $\Delta K$ values lower than $9 \mathrm{MPa} \mathrm{m}^{1 / 2}$, a high level of roughness-induced closure, which promotes higher crack growth resistance, must be expected as indeed observed in Fig. 4.

As fatigue crack growth rate has shown stress ratio dependence, a crack closure analysis was carried out to correlate the results with $\Delta K_{\text {eff }}$. The crack closure level can be represented by plotting the normalised load ratio parameter $U$, defined by Eq. (1), as a function of $\Delta K$ as depicted in Fig. 4 for aluminium alloy 2017-T4.

This figure shows that the crack closure data are basically in accordance with the observed variation in the crack growth rates presented in Fig. 2, i.e., higher closure levels for lower $\mathrm{d} a / \mathrm{d} N$ values. The values of $U$ increased with $R$, i.e., the crack closure level decreased with the stress ratio. Moreover, for $R=0$ parameter $U$ decreases with decreasing $\Delta K$, i.e., the crack closure level is more important for low $\Delta K$ values.

At $R=0.4$ there is no crack closure $(U=1)$ for $\Delta K$ values above approximately $7 \mathrm{MPa} \mathrm{m}^{1 / 2}$. However, for $\Delta K$ values lower than $7 \mathrm{MPa} \mathrm{m}^{1 / 2} U$ dropped steeply with decreasing $\Delta K$. This behaviour is related to the increase of crack closure which is promoted by oxidation and surface roughness in the near threshold regime.

However there is a significant discrepancy between the crack closure level depicted in Fig. 4 for $10 \mathrm{~mm}$ thickness specimens and the correspondent crack growth rates presented in Fig. 2 for $\Delta K$ values approximately above $10 \mathrm{MPa} \mathrm{m}^{1 / 2}$. It is proposed that this discrepancy is mainly due to the phenomenon of partial closure, i.e., the premature contact between crack faces in the initially high roughness zone while the crack faces are still open near the crack tip located in the region of lower roughness (see Fig. 3) as illustrated in Fig. 5. Therefore, a significant contribution to fatigue damage occurs in the load range below the opening load when measured remotely from the crack tip by the compliance technique.

The phenomenon of partial closure, can be taking into account by the following simple expression [10]:

$$
U^{*}=\frac{K_{\max }-\frac{2}{\pi} K_{\mathrm{op}}}{K_{\max }-K_{\min }}
$$

The values of $U^{*}$, calculated for $\Delta K$ values above $10 \mathrm{MPa} \mathrm{m}^{1 / 2}$ by Eq. (3), are also superimposed in Fig. 4 . This figure shows that the crack closure level taking into account partial closure (black circles) is still slightly high in comparison with the da/ $\mathrm{d} N$ trends observed in Fig. 2. This behaviour can be explained by the stress state expected for this thickness, because for higher thicknesses plane strain prevails and, therefore, the crack faces contact happens only in a small region near the specimen surfaces.

The change of effective stress intensity factor $\Delta K_{\text {eff }}$ can be calculated from $U$ and $\Delta K$ according to Eq. (2). The objective is to investigate whether the crack closure by itself permits the reduction of all the $\mathrm{d} a / \mathrm{d} N-\Delta K$ curves depicted in Fig. 2 to a unique curve $\mathrm{d} a / \mathrm{d} N-\Delta K_{\text {eff }}$ independent of stress ratio and specimen thickness. Fig. 6 shows the $\mathrm{d} a / \mathrm{d} N-\Delta K_{\text {eff }}$ data for aluminium alloy 2017-T4 for the 1.8 and $10 \mathrm{~mm}$ thicknesses at the two stress ratios $R=0$ and $R=0.4$ analysed. For the $10 \mathrm{~mm}$ thickness specimen at $R=0$ parameter $U^{*}$ was used for $\Delta K>10 \mathrm{MPa} \mathrm{m}^{1 / 2}$, but the results obtained without taking into account the partial closure phenomenon are also superimposed in the figure (grey circles) for comparison.

The fatigue crack growth rate data tend to fall within a very narrow scatter band when $\mathrm{d} a / \mathrm{d} N$ is plotted against $\Delta K_{\text {eff }}$ according to

$$
\frac{\mathrm{d} a}{\mathrm{~d} N}=C\left(\Delta K_{\mathrm{eff}}\right)^{m}
$$

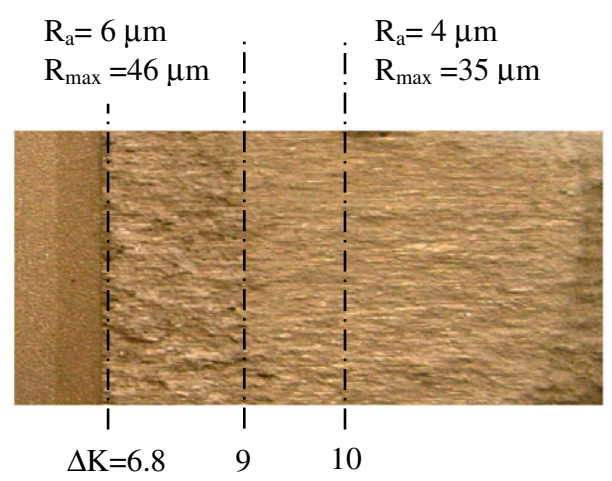

Fig. 3. Image of fatigued fracture surface of $10 \mathrm{~mm}$ thickness specimen tested under $R=0 . \Delta K$ values in MPa $\mathrm{m}^{1 / 2}$. 


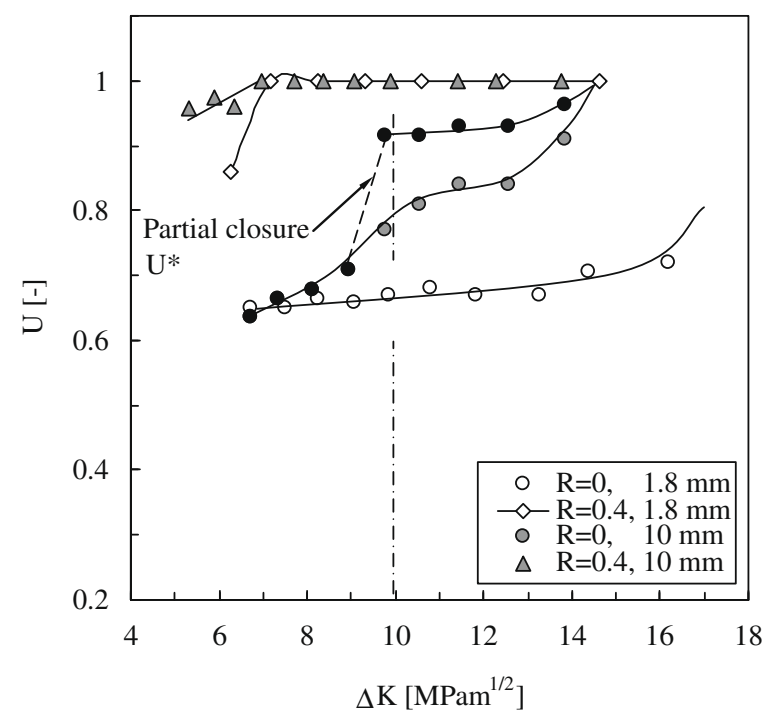

Fig. 4. Influence of the stress ratio on the crack closure level for alloy 2017-T4.

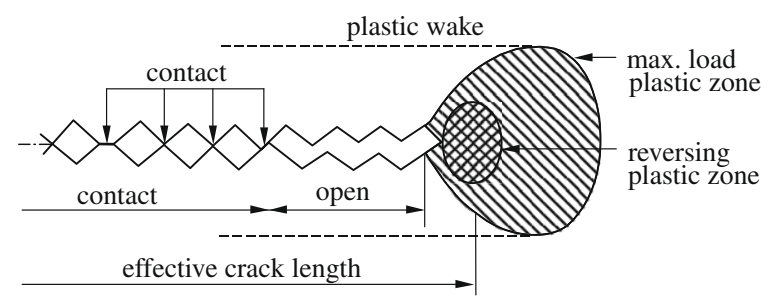

Fig. 5. The phenomenon of partial closure, after Paris et al [10].

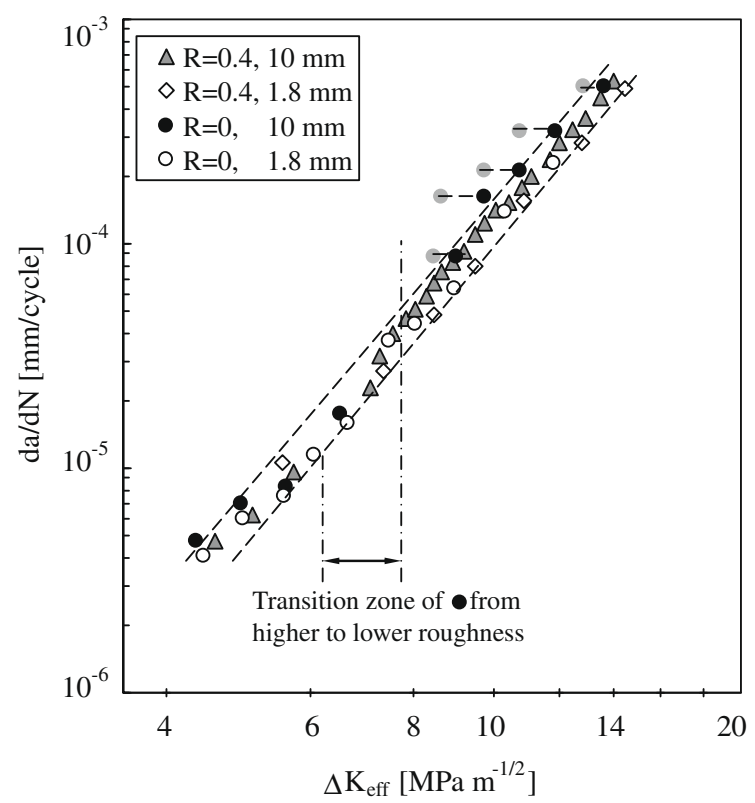

Fig. 6. Fatigue crack growth rate versus $\Delta K_{\text {eff }}$ for aluminium alloy 2017-T4. 
Therefore, crack closure by itself permits the reduction of all the $\mathrm{d} a / \mathrm{d} N-\Delta K$ curves to a unique curve $\mathrm{d} a / \mathrm{d} N-\Delta K_{\text {eff }}$ independent of the stress ratio $R$ and thickness once crack closure effect is correctly accounted for. The parameters $C$ and $m$ of Eq. (4) obtained for aluminium alloy 2017-T6 are $5.461 \times 10^{-9}\left[\mathrm{~mm} /\right.$ cycle, $\left.\mathrm{MPa} \mathrm{m}^{1 / 2}\right]$ and 4.35, respectively. These parameters were obtained with a correlation coefficient of 0.987 .

Fig. 7 compares the crack growth behaviour of alloy 2017-T4 at the stress ratio of $R=0$ with data for alloys 6082-T6(A) and 6082-T6(B) obtained in a previous work [9] This figure shows that crack growth rates for alloy 2017-T4 are significantly lower than that for alloy 6082-T6(A), and are only slightly higher than the ones obtained for alloy 6082-T6(B).

Fig. 8 presents the variation of $K_{\mathrm{op}} / K_{\max }$ as a function of $\Delta K$ at $R=0$ for all the alloys. This figure shows that the crack closure data are in accordance with the observed variation in the crack growth rates presented in Fig. 7, i.e., higher closure levels for lower $\mathrm{d} a / \mathrm{d} N$ values.

Fig. 8 also shows that in general $K_{\mathrm{op}} / K_{\max }$ decreases steeply as $\Delta K$ increases until a minimum $K_{\mathrm{op}} / K_{\max }$ value of approximately 0.2 is attained, after which this ratio remains basically constant. For alloy 6082-T6(A) the constant $K_{\text {op }} / K_{\max }$ ratio is achieved at $\Delta K=5.5 \mathrm{MPa} \mathrm{m}{ }^{1 / 2}$. For higher values of $\Delta K$ closure values are generally independent of $\Delta K$. For alloys 6082-T6(B) and 2017-T4 this condition was not attained. From the trend of the curve for these alloy, $K_{\mathrm{op}} / K_{\max }=0.2$ is estimated to occur only after $\Delta K=20 \mathrm{MPa} \mathrm{m}^{1 / 2}$.

Images of the fatigued fracture surface of $\mathrm{M}(\mathrm{T})$ specimens tested at $R=0$ for the three alloys are compared in Fig. 9. It can be clearly seen that alloys 2017-T4 and 6082-T6(B) have a considerable more irregular surface topography than alloy 6082T6(A). The surface roughness of the fatigued fracture surfaces was also evaluated. The values of $R_{\mathrm{a}}$ and $R_{\max }$ are superimposed in Fig. 9.

Although the roughness is characterized by a significant scatter, alloy 6082-T6(B) presented a relative higher roughness in comparison to alloy 2017-T4. Furthermore, these measurements showed that for alloys 2017-T4 and 6082-T6(B) the mean values of $R_{\max }$ were at least 2 and 3 times higher, respectively, in comparison to alloy 6082-T6(A), suggesting an effect of roughness in the high crack closure level observed for these alloys.

In the work of Bergner et al [5] aluminium alloys were classified in two distinct groups. One of the groups (denoted "I") is characterised by approximately equal crack growth rates at $\Delta K_{0}=10 \mathrm{MPa} \mathrm{m}^{1 / 2}$, of about $(1.65 \pm 0.45) \times 10^{-4} \mathrm{~mm} / \mathrm{cycle}$. In contrast, the other group (denoted "II") is characterised by varying $\mathrm{d} a / \mathrm{d} N$ at $\Delta K_{0}$. Crack growth rates of group II are always lower than those observed for group I. They propose that the main criterion of differentiation between the alloys of groups I and II is whether an alloy shows, respectively, plasticity-induced closure only or additionally other retarding mechanisms such as roughness-induced closure.

Due to the higher degree of coherency of the main strengthening precipitates with the aluminium lattice for naturally aged conditions, they are mainly sheared by dislocations promoting planar slip conducing to a higher roughness due to an extensive crack deflection. Therefore, the naturally aged aluminium alloys are classified in group II [5]. Artificially aged conditions such as T6, having a lower coherency of its precipitates with the aluminium lattice, a lower crack deflection and roughness are expected because a significant fraction of precipitates are looped or bypassed. Thus, they are included in group I [5].

Fig. 6 shows that alloy 6082-T6(A) being in artificially aged condition T6 and alloy 2017-T4 being in naturally aged condition T4 are agreement of the above statements, as they present crack growth rates of approximately $1.69 \times 10^{-4}$ and

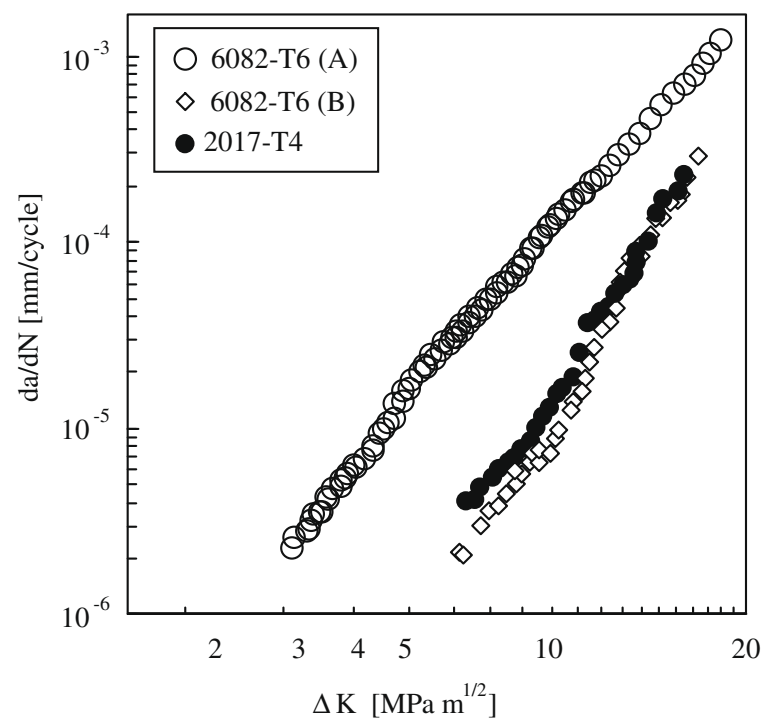

Fig. 7. Fatigue crack growth rates for different heat-treated aluminium alloys at $R=0$. 


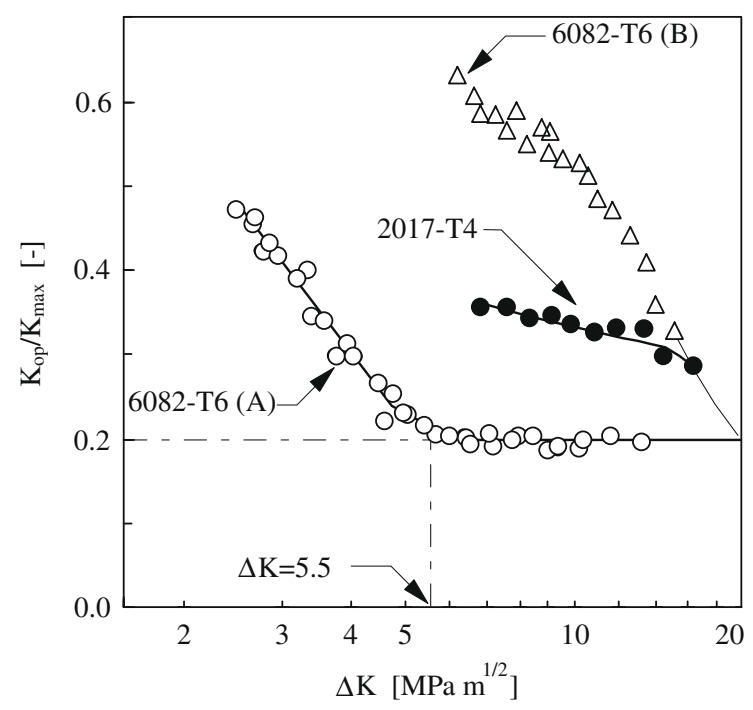

Fig. 8. Crack closure data for aluminium alloys. $R=0$.

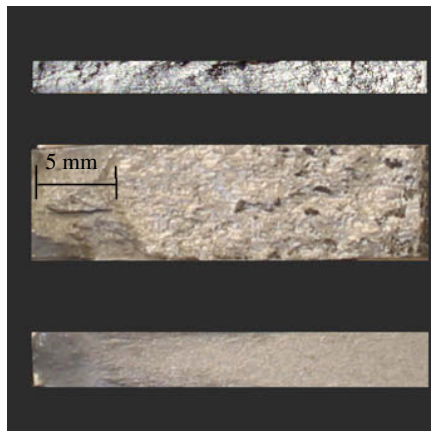

$$
\begin{aligned}
& 2017-\mathrm{T} 4 \\
& \mathrm{R}_{\mathrm{a}}=4 \mu \mathrm{m} \\
& \mathrm{R}_{\max }=37 \mu \mathrm{m} \\
& 6082-\mathrm{T} 6(\mathrm{~B}) \\
& \mathrm{R}_{\mathrm{a}}=6.5 \mu \mathrm{m} \\
& \mathrm{R}_{\max }=45 \mu \mathrm{m} \\
& \\
& 6082-\mathrm{T} 6(\mathrm{~A}) \\
& \mathrm{R}_{\mathrm{a}}=3 \mu \mathrm{m} \\
& \mathrm{R}_{\max }=15 \mu \mathrm{m}
\end{aligned}
$$

Fig. 9. Images of specimens fatigued fracture surfaces.

$2 \times 10^{-5} \mathrm{~mm} /$ cycle at $\Delta K_{0}=10 \mathrm{MPa} \mathrm{m}^{1 / 2}$, respectively. However, alloy 6082-T6(B), although being in the same artificially aged condition T6 as alloy 6082-T6(A), has significantly lower values of $\mathrm{d} a / \mathrm{d} N$ at $\Delta K_{0}$, approximately $7.5 \times 10^{-6} \mathrm{~mm} / \mathrm{cycl}$, respectively, being better included in group II.

The basic distinction between the 6082-T6 alloys analysed in this work is the amount of Mn and $\mathrm{Cr}$ added as dispersoidforming elements. Although, some influence of the age-hardening heat treatment cannot be discharge, the lower crack growth rates observed for alloy 6082-T6(B), in comparison to 6082-T6(A), can be mainly attributed to the higher dispersoid contend in alloy 6082-T6(B). This effect enhances roughness-induced crack closure and, thus, improves the fatigue properties [6].

Therefore, it is suggested that distinct closure mechanisms must exist in the alloys. For alloy 6082-T6(A) plasticity and roughness-induced crack closures must be present, being the last significant only near threshold. For the other alloys roughness-induced closure must also be dominate in the Paris regime.

\section{Conclusions}

From the experimental study on fatigue crack growth behaviour in several heat-treated aluminium alloys the following concluding remarks can be drawn:

1. A strong stress ratio and material dependence effects on the fatigue crack growth were observed

2. Specimen thickness has no significant influence in the crack growth behaviour of alloy 2017-T4.

3. For alloy 2017-T4 crack closure by itself permits the reduction of all the propagation curves to a unique curve da/ $\mathrm{d} N-\Delta K_{\text {eff }}$ independent of the stress ratio and thickness once crack closure effect is correctly accounted for.

4. The crack growth behaviour of heat-treated aluminium alloys depends mainly on whether the dominant closure mechanism is plasticity-induced or roughness-induced. The enhancement of roughness-induced closure promotes higher crack growth resistance in these alloys. 
5. In the alloy 6082 age hardened by artificially ageing and simultaneously with a lower content of Mn and Cr elements plasticity-induced closure is dominant.

6. Roughness-induced closure dominates crack closure in alloys age hardened by naturally ageing and also artificially aged 6082 alloys with higher contents of $\mathrm{Mn}$ and $\mathrm{Cr}$ elements.

\section{Acknowledgments}

The authors would like to acknowledge POCI programme, Project POCTI/EME/47022/2002, for funding the work reported.

\section{References}

[1] Blom AF, Holm DK. An experimental and numerical study of fatigue crack closure. Eng Fract Mech 1985;22:997-1011.

[2] Elber W. The significance of fatigue crack closure. In: Damage tolerance in aircraft structures, ASTM STP 486. Philadelphia: ASTM; 1971. p. 230-42.

[3] Petit J, Mendez J. Some aspects of the influence of microstructure on fatigue resistance. In: Lutjering G, Nowack H, editors. Fatigue '96: Proceedings of the sixth international fatigue congress, vol. I. Oxford: Pergamon; 1996. p. 15-26.

[4] Bergner F, Zouhar G. A new approach to the correlation between the coefficient and the exponent in the power law equation of fatigue crack growth. Int J Fatigue 2000;22:229-39.

[5] Bergner F, Zouhar G, Tempus G. The material-dependent variability of fatigue crack growth rates of aluminium alloys in the Paris regime. Int J Fatigue $2001 ; 23: 383-94$.

[6] Scheffel R, Detert K. Near threshold crack propagation and crack closure in Al-Mg-Si alloys with varying manganese concentration. In: Van Elst HC, Bakker A, editors. Fracture control of engineering structures. ECF6: proceedings of the sixth European Conference on fracture, vol. III. UK: EMAS publications; 1986. p. 1511-21.

[7] American Society for Testing and Materials. Standard test method for microhardness of materials. Annual book of ASTM standards, vol. 03.01; 2000 [ASTM E 647].

[8] Allison JE, Ku RC, Pompetzki MA. A comparison of measurement methods and numerical procedures for the experimental characterization of fatigue crack closure. In: Newman JC, Elber W, editors. Mechanics of fatigue crack closure, ASTM STP 982. Philadelphia (PA): ASTM; 1988. p. 171-85.

[9] Borrego LP, Costa JM, Silva S, Ferreira JM. Microstructure dependent fatigue crack growth in aged hardened aluminium alloys. Int J Fatigue 2004;26:1321-31.

[10] Paris PC, Tada H, Donald JK. Service load fatigue damage - a historical perspective. Int J Fatigue 1999;21(Suppl.):S35-46. 